\title{
CBCT: A Guide to Post-Treatment Evaluation or Health Hazard!!
}

\author{
Vaibhav Karemore ${ }^{1}$, Tapasya Karemore ${ }^{2 *}$ and Smriti Golhar ${ }^{2}$ \\ ${ }^{1}$ Department of Perodontics, Govt Dental College Nagpur, India \\ ${ }^{2}$ Department of Oral Medicine \& Radiology, VSPM'S Dental College \& Research Center, India
}

*Corresponding author: Tapasya Karemore, Associate Professor, Department of Oral Medicine \& Radiology, VSPM'S Dental College \& Research Center, Digdoh hills Hingna, Nagpur, India

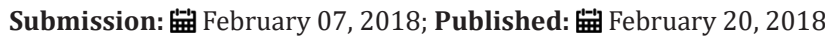

\section{Introduction}

Limitations of 2D radiographs can be eliminated with the help of 3D imaging such as cone beam computed tomography. All CBCT units provide axial, coronal and sagittal multi-planar reconstructed images without magnification. Geometric distortion and superimpositions, the major setbacks of 2D imaging were corrected by CBCT and so its benefits were appreciated.

Different CBCT systems were launched with different field of views till now (FOVs). CBCT can be used to image small areas without unnecessary exposure to patient by selecting appropriate FOV size [1]. Generally, smaller scan volume gives higher the spatial resolution to the image. Selection of FOV depends upon site of interests. Its influence in diagnosing simulated periapical lesions was studied by Hedesiu et al. [1] which showed that FOV size did not show any difference in diagnostic performance. This fact helps to assume that with optimum dose diagnostic details can be obtained for minute PDL changes or other pathologies [2].

Though CBCT and its use in dentistry proven, it is not in focus when considered in the subject of periodontology. Radiographs were always proven as adjunct modality along with clinical signs and symptoms in periodontal diseases. CBCT has isotropic voxel size, better image quality with which alveolar bone defects can be evaluated with highest accuracy. It is also documented that CBCT has better diagnostic accuracy in the detection of inter-radicular periodontal bone defects. ST-CBCT, a modified practical method was utilized to determine the dimension and relationship of the structures of the dento-gingival unit. But this method could provide only quantitative assessment.

Periapical index based on CBCT for indentification of AP was used to measure destruction of periapical alveolar bone where it was found that CBCT imaging detected $54.2 \%$ more AP lesions than conventional radiography [3-5]. The study by Patel et al also concludes that CBCT is superior in diagnosing periapical periodontitis $[1,3,5]$. Liang et al. reported sensitivity, specificity, and accuracy values for CBCT were 1 and for PR, 0.64,1, and 0.79 , respectively in detecting artificially created lesions [6] CBCT generated 3D images are accurate for the diagnosis of intra bony defects, furcation involvements and buccal or lingual bone destructions.

Studies were conducted to analyse and also to compare various bone defects, fenestrations and severe bone involvements. With few limitations, such as, high contrast resolution leading to inefficiency for detecting soft tissue changes with the known facts of radiation dose and high cost, CBCT can be proved as effective tool to diagnose periodontal health conditions.

To ponder on the indication of CBCT and dose related issues in periodontal conditions, its use is restricted in many clinical studies. This may be due to demand of repeated scan to see postoperative changes and danger of excess dose than permissible, to patient. Can we rethink on this issue or modify the study design to incorporate required scans? Meticulous study design with possible effective dose calculations may help clinician to use CBCT as a boon to get exact bone changes.

\section{References}

1. Hedesiu M, Baciut M, Baciut G, Nackaerts O, Jacobs R (2012) Comparison of cone beam CT device and field of view for the detection of simulated periapical bone lesions. Dentomaxillofac Radiol 41(7): 548-552.

2. Venskutonis T, Daugela P, Strazdas M, Juodzbalys G (2014) Accuracy of digital radiography and cone beam computed tomography on periapical radiolucency detection in endodontically treated teeth. J Oral Maxillofac Res 5(2): e1.

3. Balasundaram A, Shah P, Hoen M, Wheater M, Bringas J, et al. (2012) Comparison of cone -beam computed tomography in predicting treatment decision for periapical lesions: A clinical study. International Journal of Dentistry 2012(2012): 1-8.

4. Patel S, Wilson R, Dawood A, Mannocci F (2012) The detection of periapical pathosis using periapical radiography and cone beam computed tomography-Part 1: pre-operative status. Int Endod J 45(8): 702-710.

5. Patel S, Dawood A, Mannocci F, Wilson R, Pitt Ford T (2009) Detection of periapical bone defects in human jaws using cone beam computed tomography and intraoral radiography. Int Endod J 42(6): 507-515.

6. Maillet M, Bowles WR, McClanahan SL, John MT, Ahmad M (2011) Cone beam computed tomography evaluation of maxillary sinusitis. J Endod 37(6): 753-757. 
Creative Commons Attribution 4.0

International License

For possible submissions Click Here

\section{Your subsequent submission with Crimson Publishers} will attain the below benefits

- High-level peer review and editorial services

- Freely accessible online immediately upon publication

- Authors retain the copyright to their work

- Licensing it under a Creative Commons license

- Visibility through different online platforms

- Global attainment for your research

- Article availability in different formats (Pdf, E-pub, Full Text)

- Endless customer service

- Reasonable Membership services

- Reprints availability upon request

- One step article tracking system 